\title{
Chapter 10 \\ Social Computing and Cooperation Services for Connected Government and Cross-Boundary Services Delivery
}

\author{
Walter Castelnovo \\ University of Insubria, Italy
}

\begin{abstract}
Connected Government requires different governmentorganizations to connect seamlessly across functions, agencies, and jurisdictions in order to deliver effective and efficient services to citizens and businesses. In the countries of the European Union, this also involves the possibility of delivering cross-border services, which is an important step toward a truly united Europe. To achieve this goal, European citizens and businesses should be able to interact with different public administrations in different Member States in a seamless way to perceive them as a single entity. Interoperability, which is a key factor for Connected Government, is not enough in order to achieve this result, since it usually does not consider the social dimension of organizations. This dimension is at the basis of co-operability, which is a form of non-technical interoperability that allows different organizations to function together essentially as a single organization. In this chapter, it is argued that, due to their unique capacity of coupling several technologies and processes with interpersonal styles, awareness, communication tools, and conversational models, the integration of social computing services and tools within inter-organizational workflows can make them more efficient and effective. It can also support the "learning" process that leads different organizations to achieve co-operability.
\end{abstract}

\section{INTRODUCTION}

Under the pressure of the current global economic crisis, many governments boosted the e-Government's strategic role in supporting the economic recovery (Ubaldi, 2011). The European Union identified e-government as a fundamental element of the Digital Agenda for Europe (DAE) and considered it as one of the seven Flagship Initiatives stated in the EU's 2020 strategy for smart,

DOI: $10.4018 / 978-1-4666-6082-3 . c h 010$

Copyright $\odot$ 2014, IGI Global. Copying or distributing in print or electronic forms without written permission of IGI Global is prohibited. 
sustainable and inclusive growth (EC, 2010). One of the main objectives of the DAE is the use of Information and Communication Technologies (ICT) to foster the establishment of a Single Internal Market involving all the Member States since this could have a relevant impact on the EU's economy. Actually, the full development of the Single Market by 2020 is expected to increase the EU's GDP by an extra 4\% that corresponds to a $€$ 500-billion gain (EPC, 2010). The EU's strategy for attaining this objective identifies four drivers (EC, 2012):

- Developing fully integrated networks in the Single Market;

- Fostering mobility of citizens and businesses across borders;

- $\quad$ Supporting the digital economy across Europe;

- $\quad$ Strengthening social entrepreneurship, cohesion and consumer confidence

Among these, crucial for the attainment of the objective of the Single Market, is the mobility of citizens and businesses across borders. According to a European Commission's estimate (EC, 2013), there were approximately 1,790,000 immigrants and commuters between EU Member States in 2009 with an estimated growth of $22.7 \%$ by 2020 (reaching 2,196,035 individuals per annum in 2020). Besides fostering economic growth, mobility of both citizens and enterprises among the Member States can contribute substantially to strengthening the European citizens' perception of living and working in a Single Market. However, this objective can be achieved at the condition that entrepreneurs can set up and run a business anywhere in Europe independently of their original location, and that citizens are allowed to study, work, reside and retire anywhere in the EU. To guarantee these conditions to European citizens and entrepreneurs, the public administration agencies in the Member States should be able to provide seamless, interoperable and sustainable cross-border public services.

The availability of cross-border services could have a significant impact on citizens and enterprises mobility across the EU Member States. In EC (2013), it is estimated that there would be a total demand of 1,262,887 users for cross-border services besides 140,000 branches and immigrant business start-ups between EU Member States that could utilize cross-border business services. However, to deliver cross-border services, the public administration agencies of different Member States are required to connect seamlessly across functions, agencies, and jurisdictions to deliver effective and efficient services to citizens and businesses. This would allow European public administration agencies to act as a single organization, so that citizens feel that a single (virtually integrated) organization is serving them rather than a number of different public authorities, possibly from different Member States. From this point of view, to satisfy the demand of cross-border services and to strengthen the European citizens' perception of living and working in a Single Market (which are crucial for the attainment of the objectives stated by EU's 2020 strategy), the Member States should transform their government systems toward the Connected Government model (Pallab, 2010) at both the national and the European Union level.

Connected government is usually considered as a multi-dimensional construct (Kaczorowski, 2004; Pallab, 2010), including dimensions such as:

- Citizen centricity, as the guiding principle for the public sector transformation processes, whose goal is to create greater value for citizens, not only for citizens as users/consumers or beneficiaries, but also for citizens as taxpayers, as participants in the democratic processes, as policy makers and employees in public administration 
agencies and as suppliers and entrepreneurs as well (Bannister, 2002; Castelnovo \& Simonetta, 2007, Castelnovo, 2013).

- Back-office reorganization, to force the public administration agencies to "rethink their operations to move from being system-oriented to chain-oriented with respect to their structure, functioning, skills and capabilities, and culture and management" (UNDESA, 2008).

- Networked organizational model, to transform a fragmented system of government agencies in a networked virtual organization that operates seamlessly toward a common mission, that is to deliver more value to citizens and enterprises (Johnston, 2006).

- Standardized infrastructure and interoperability, as the condition that makes it possible to achieve the vertical integration among different levels of Government as well as the horizontal integration among government organizations belonging to the same institutional level (Microsoft, 2011).

- Public sector governance, to guarantee the consistency of the transformation processes implemented both at the Central and the Local Government level, and to assure that all the transformation processes preserve the public interest and increase the value for citizens (Castelnovo, 2012).

- Social inclusion, as a way to bridge the gap between government and citizens, to build trust in government and to assure that no citizen is left behind.

Achieving the objective of connected government at the EU level is not a simple matter at all. It involves 27 different central government systems, 89,149 municipalities, 1,126 second tier Local Government organizations and 105 third tier Local Government organizations (CEMR, 2011).
Moreover, to these it should be added a number of government agencies that in some countries are directly involved in the delivery of services to citizens and enterprises. This raises the problem of how the horizontal and vertical integration/cooperation among government bodies and agencies (that is instrumental for connected government) can be achieved within and across highly fragmented systems of (Local) Government.

This problem is particularly apparent when considered from the point of view of crossborder inter-agencies cooperation. However, the cross-border level simply magnifies problems that already affect inter-agencies cooperation at the level of the single states. Without achieving the connectedness of government agencies at the level of the single states there is no hope to achieve the level of cross-border connectedness required for the delivery of cross-border services. Based on this observation, in this chapter I will be concerned with the problem of how horizontal integration/cooperation among government agencies can be achieved in Local Government, especially in those countries whose system of Local Government is characterized by a high administrative fragmentation and by the prevalence of small municipalities. My claim is that the Social Computing and Collaboration Services and tools (SC\&CSs) made available by the so-called Web 2.0 paradigm provide powerful tools for supporting inter-agencies cooperation and the development of a connected system of Local Government as a first step toward a virtually integrated/connected system of European public administrations.

This chapter is organized as follows. The next section discusses interoperability as the platform on which connected government can be based. Here, I will show how, in order to guarantee interagencies cooperation, a concept of non-technical interoperability is needed, similar to the concept of co-operability as defined in the Command \& Control literature. In the section that follows, I will 
argue that the sharing of a cooperation environment and a cooperation platform among different organizations can help them to achieve co-operability. More specifically, I will suggest including in the cooperation platform the Social Computing and Cooperation Services and tools typical of the Enterprise 2.0 paradigm. Furthermore, I will discuss the possibility of using SC\&CSs to support trustbuilding processes among the people involved in inter-agencies cooperation, the standardization of the operative processes and the establishment of a shared system of values and a shared organizational culture. Finally, with reference to the case of One Stop Shop for Production Activities in Italy, which represents a typical service of (Connected) e-Government, in the last section of the chapter I will consider how SC\&CSs can be used to support the execution of inter-organizational workflows. This will exemplify the use of Social Computing and Cooperation services and tools in cases in which the delivery of services crosses organizational boundaries (i.e., cross-border, cross-administrative and cross-sectorial service delivery).

\section{INTEROPERABILITY AS THE PLATFORM FOR CONNECTED GOVERNMENT}

According to EIF (2010), a cross-border public sector service is a service supplied by public administrations (either national public administrations at any level, or bodies acting on their behalf, and/or EU public administrations) either to one another or to European businesses and citizens. The EU's approach to cross-border services as described, for instance, in EC (2013) focuses exclusively on online cross-border services; however, as explicitly recognized in EIF (2010), in order to satisfy the principles of inclusion and accessibility traditional paper-based and/or face-to-face service delivery needs (at least) to co-exist with electronic delivery. Actually, mainly due to complexity and security concerns (and to the fact that paper, mail or personal visits are still necessary to use an electronic service), despite their online availability many services are still accessed offline by European citizens and businesses, as shown in Table 1 that reports data collected through a survey involving European citizens and businesses.

Table 1. e-Government citizens and business services per usage level (EC, 2013)

\begin{tabular}{|c|c|c|c|c|c|}
\hline \multicolumn{2}{|c|}{ Service } & Usage & Accessed Online & Accessed Offline & Both \\
\hline \multirow{7}{*}{ 记 } & Income tax declaration & $66,6 \%$ & $48,3 \%$ & $35,8 \%$ & $15,9 \%$ \\
\hline & ID request & $65,8 \%$ & $65,8 \%$ & $58,6 \%$ & $17,8 \%$ \\
\hline & Vehicle tax & $56,5 \%$ & $49,9 \%$ & $38,8 \%$ & $11,3 \%$ \\
\hline & Enroll as a student & $43,2 \%$ & $49,5 \%$ & $27,7 \%$ & $22,7 \%$ \\
\hline & Ordering a birth certificate & $33,2 \%$ & $40,4 \%$ & $47,1 \%$ & $12,5 \%$ \\
\hline & Register for a pension & $16,2 \%$ & $19,4 \%$ & $64,5 \%$ & $16,1 \%$ \\
\hline & Register for legal aid & $14,5 \%$ & $31,4 \%$ & $60,5 \%$ & $8,1 \%$ \\
\hline \multirow{4}{*}{ 唇 } & Business tax declaration & $56,8 \%$ & $46,9 \%$ & $35,4 \%$ & $17,7 \%$ \\
\hline & Consult a business register & $37,1 \%$ & $61,4 \%$ & $2,9 \%$ & $22,4 \%$ \\
\hline & Establish a new legal entity & $27,1 \%$ & $45,2 \%$ & $46,8 \%$ & $8,1 \%$ \\
\hline & Submitting a tender & $21,4 \%$ & $46,9 \%$ & $22,4 \%$ & $28,6 \%$ \\
\hline
\end{tabular}


The data reported in Table 1 clearly show that in the implementation of cross-border services both online and offline (face-to-face, paper based) interactions between citizens/businesses and public administrations should be taken into the account, especially if cross-border services are to be considered as a means to strengthen the European citizens' perception of living and working in a Single Market.

The basic service scenario I will consider in this chapter is the following: An enterprise E established in Member State X, wishing to establish in Member State Y, submits a request (eitheronline or offline) for establishment in Member State Y. To process this request:

- $\quad$ E could be required to interact (either online or offline) with a public administration A in State Y.

- Public administration A could need to exchange information with a public body in State $X$ and then use this information in the execution of inter-organizational workflows involving other public agencies in State Y.

Under this service scenario, to let European citizens/entrepreneurs experience seamless crossborder services across Europe, it is necessary (i) to make citizens' interactions with public administrations across Europe as similar as possible; and (ii) to allow public administrations from different Member States to achieve high levels of cooperation/integration. In both cases, the problem is how to achieve this result, especially when at the Member State level the delivery of the services involves different agencies to which the institutional system in force assigns different competences.

The first and most obvious answer to this problem is interoperability; indeed, as stated in UNDESA (2008): The key platform on which connected government is built upon is the concept of interoperability which is the ability of government organizations to share and integrate information by using common standards.

Interoperability lies at the basis of the EU's approach to cross-border services delivery. Actually, the fundamental role of interoperability has been clearly pointed out at least since the adoption of the "eEurope Action Plan 2005" at the Seville summit in 2002 (EC, 2002). Indeed, in that Action Plan the objective was explicitly stated "to issue an agreed interoperability framework to support the delivery of pan-European e-Government services to citizens and enterprises" (EC, 2002, p. 10). This framework has actually been delivered in 2010 and the Member States have been invited to align their National Interoperability Frameworks (NIFs) with the European Interoperability Framework (EIF). The EIF has been designed to allow not only cross-border services but also cross-sectorial and cross-administrative services. This means that it should be considered as the basis for inter-organizational cooperation for the delivery of services originating at all the layers of government, i.e. at the local, the regional, the national and the EU level.

The EIF assumes the following definition of interoperability and interoperability framework (EIF, 2010, p. 2):

Interoperability, within the context of European public service delivery, is the ability of disparate and diverse organizations to interact towards mutuallybeneficial and agreed common goals, involving the sharing of information and knowledge between the organizations, through the business processes they support, by means of the exchange of data between their respective ICT systems.

An interoperability framework is an agreed approach to interoperability for organizations that wish to work together towards the joint delivery of public services. Within its scope of applicability, it specifies a set of common elements such as 
vocabulary, concepts, principles, policies, guidelines, recommendations, standards, specifications and practices.

The EIF considers four levels of interoperability, each of which must be taken into account when defining cross-border/sectorial/administrative services (cross-boundary services henceforth). The four levels are:

- Technical Interoperability: Which concerns the planning of technical issues involved in linking IT systems and services. Technical interoperability includes key aspects such as open interfaces, interconnection services, data integration and middleware, data presentation and exchange, accessibility and security services.

- Semantic Interoperability: Which concerns the meaning of exchanged information that has to be preserved by all parties. Semantic interoperability defines the exact format of the information to be exchanged and ensures that the meaning of exchanged information is understandable by any other application that can combine the received information with other information resources and process it in a meaningful manner.

- Organizational Interoperability: Which concerns the coordination of processes in which different organizations achieve a previously agreed and mutually beneficial goal. Organizational interoperability is concerned with bringing about the collaboration of administrations that wish to exchange information and may have different internal structures and processes. This includes aligning business processes and related data exchange, as well as meet the requirements of the user community by making services available, easily identifiable, accessible and user-focused.
- Legal Interoperability: which concerns the alignment of legislations so that exchanged data is accorded proper legal weight. Legal interoperability assures that the legal validity of the information exchanged to provide services is maintained across borders and data protection legislation in both originating and receiving countries is respected.

Moreover, besides the four level of interoperability the framework emphasizes the role of the political context to facilitate cooperation among public administrations. Indeed, the political context must be considered to achieve interoperability because "for effective cooperation, all stakeholders involved must share visions, agree on objectives and align priorities" (EIF, 2010, p. 21).

According to the EIF, all these objectives can be achieved by requiring all the organizations involved to formalize cooperation arrangements in interoperability agreements (for each level of interoperability considered in the EIF). However, as explicitly recognized in (EIF, 2010, 28):

ensuring interoperability between legal instruments, organization business processes, information exchanges, services and components that support the delivery of a European public service is a continuous task, as interoperability is disrupted by changes to the environment, i.e. to legislation, the needs of businesses orcitizens, the organization of public administrations, business processes or technologies.

Although, the signing of interoperability agreements (at all layers of government) certainly is a necessary condition for cooperation among different public administrations, it is at least dubious that it is also a sufficient condition to maintain interoperability over time in a complex and changing environment. Indeed, the political, institutional and organizational heterogeneity between public administrations (both within and across Member 
States) can affect interoperability (Misuraca, Alfano \& Viscusi, 2011). Due to the political, institutional and organizational heterogeneity of Member States' public administration systems, in order to maintain interoperability over time some form of inter-organizational compatibility should be pursued at all layers of government as a way to improve inter-organizational (cross-boundary) cooperation. This includes the sharing of visions, objectives and priorities that can be ratified in cooperation agreements, but that cannot be achieved simply by signing those agreements.

\section{BEYOND INTEROPERABILITY}

The conditions that define the four interoperability levels (plus the political context) considered in the EIF are focused toward enabling the automatic exchange of data between the ICT systems of the public organizations that cooperate for the delivery of services. Indeed, in the service scenario considered in (EIF, 2010) citizens/businesses from one Member State $\mathrm{X}$ directly interact (online) with public administrations in another Member State $\mathrm{Y}$ that deliver online the services they required. The satisfaction of the interoperability requirements defined by the EIF is expected to allow the public administrations involved to exchange efficiently and effectively the information they need to deliver the required services.

However, the effectiveness of inter-organizational information exchange and integration heavily depends on interactions among social and technical processes both at the intra-organizational and at the inter-organizational level (Pardo, Cresswell, Dawes \& Burke, 2004). From this point of view, even when it simply involves information exchanges among different organizations, the delivery of cross-boundary services through connected government should be considered as based on a complex networked socio-technical system (more specifically, a socio-technical system of systems). In such a socio-technical system, hu- man participants and IT systems from different organizations perform processes using information and other resources to produce services for internal or external users (Alter, 2006). Scholl and Klischewski (2007) describe nine factors that constraint government integration and interoperability. These are:

\section{- Constitutional/Legal Constraints:}

Integration and interoperation may be outright unconstitutional because the democratic constitution requires powers to be divided into separate levels and branches of government. Total integration and interoperability between and among branches and levels would virtually offset that constitutional imperative of checks and balances.

- Jurisdictional Constraints: Since under the constitution, governmental and nongovernmental constituencies operate independently from each other, they own their information and business processes. Due to this, their collaboration, integration and efforts towards achieving various levels of interoperability are voluntary.

- Collaborative Constraints: Organizations are distinct in terms of their disposition and readiness for collaboration and interoperation with others. Past experience, socio-political organization, and leadership style influence the degree of proneness and adeptness of potential interoperation.

- Organizational Constraints: Organizational processes and resources may differ between organizations to such an extent that integration and interoperation might prove exceedingly difficult to achieve without standardizing processes, systems, and policies.

- Informational Constraints: While transactional information might be more readily shared, strategic and organizational information might not. In addition, information quality issues arise when integrating infor- 
mation sources across various domains of control and quality standards.

- Managerial Constraints: Interoperation becomes inherently more complex as more parties with incongruent interests and needs become involved. As a result, the demands of the respective management task might exceed the management capacity of interoperating partners.

- Cost Constraints: Integration and interoperation between diverse constituencies might be limited to the lowest common denominator in terms of availability of funds. Also, unexpected budget constraints might pose serious challenges to long-term interoperation projects.

- Technological Constraints: The heterogeneity of e-Government information system platform and networking capabilities might limit the interoperation of systems to relatively low standards.

- Performance Constraints: As performance tests suggest, the higher the number of interoperating partners the lower the overall system performance in terms of response time. Yet, the focus on prioritized needs might enable fewer but more effective interoperations

Some of these constraints are considered in the EIF, as part of either one of the four levels of interoperability it defines or the political context. Some other constraints, most notably the collaborative and the managerial ones, have not been properly accounted for in the EIF. These constraints mainly depend on the social dimension of inter-organizational cooperation, which includes "human factors" such as feelings, motivation, trust, communication, culture, personal relationships, goals, values and commitment. These human factors could heavily affect the effectiveness of inter-organizational cooperation, even in case it only amounts to the sharing of information. Thus, in order to allow the delivery of cross-boundary services besides technical issues also human factors should be taken into the account, which have not been properly considered in the EIF.

The impact of human factors on the effectiveness of the delivery of seamless cross-boundary services is even more critical when the delivery of the services also requires some offline (face-to face and/or paperbased) activities to be performed, as it happens in the service scenario described above. Actually, in this case the delivery of the services does not depend only on the interchange of information among different organizations, enabled by interoperability (as defined in the EIF). In this service scenario in accessing crossboundary services citizens and businesses could experience not only differences in legislations but also differences in the following:

- Political contexts, both at the national and at the local level (characterized by different priorities, strategies and objectives).

- Administrative traditions and management styles.

- $\quad$ Procedures (of different complexities and lengths).

- Work practices and public servants' skills, and, in the case of cross-border services, even in languages.

All these elements make it very unlikely for citizens/businesses to experience seamless crossboundary services across Europe. If this will not reduce the citizens' (and businesses') mobility in the Internal Market, it certainly will not contribute to strengthen the European citizens' perception of living and working in a Single Market.

Although, they are not covered by the four levels of interoperability considered in EIF (2010), the elements mentioned above can nevertheless be accounted for in terms of some form of "in- 
teroperability," even though different from the one considered in the EIF. Indeed, to deliver seamless cross-boundary services, different public administrations have to be able not only to share information efficiently and effectively, but also to operate in a so seamless and integrated way to be perceived as parts of a single (virtual and networked) system of (European) public administrations. This requires different public administrations to share conditions that can increase inter-organizational compatibility, in terms of "standardization" at the level of operational processes, organizational architectures, management styles, culture and value systems as well as vision and strategy. By making different organizations more and more compatible, this form of organizational interoperability (that cannot be reduced to the organizational dimension of interoperability as defined in (EIF, 2010)) can strengthen inter-organizational (cross-boundary) cooperation much more than the signing of cooperation/interoperability agreements can do. This would affect the efficiency and effectiveness of the (online and offline) delivery of cross-boundary services, which represents a value for the users of those services. However, organizational compatibility would also allow European citizens to interact with public administrations in different Member States as if they were all members of a (virtually) integrated system of European public administrations, which would contribute to strengthen the European citizens' perception of living and working in a Single Market.

The concept of organizational compatibility can be described more precisely in terms of $\mathrm{co}^{-}$ operability, as it has been defined in the context of joint and multinational military operations (Clark \& Jones, 1999; Tolk, 2003; Stewart et al., 2004). Co-operability represents a form of nontechnical interoperability aiming at the successful bridging of differences in doctrine, organization, concepts of operation, and culture so that different organizations can function together essentially as a single organization with no loss in effectiveness (US-CREST, 2000; Gompert \& Nerlich, 2002).
Co-operability goes beyond the conditions that enable information exchange among different organizations; it considers also the willingness to interact and the desire to communicate clearly (Alberts, Huber \& Moffat, 2010).

Co-operability can be defined based on four attributes that summarize different aspects characterizing inter-organizational cooperation (Clark \& Jones, 1999), viz:

- Preparedness: This attribute describes the preparedness of both the organization and its members to interoperate. It is made up of doctrine, experience and training.

- Understanding: The understanding attribute measures the amount of communication and sharing of knowledge and information within the organization and explains how the information is used.

- Command Style: This attribute describes the management and command style of the organization - how decisions are made and how roles and responsibilities are allocated/delegated.

- Ethos: The ethos attribute concerns the culture and value systems of the organization, its goals and aspiration.

These attributes allow describing different levels of co-operability, characterized by a growing degree of organizational compatibility among different organizations, as defined in Table 2.

The co-operability attributes mainly concern the human factors that could influence the effectiveness of inter-organizational cooperation; from this point of view, co-operability can be considered as a complement of the four levels of interoperability defined in the EIF. The sharing of both interoperability and co-operability conditions allows different government organizations to achieve higher levels of efficiency and effectiveness in their interactions, which could mean better cross-boundary services. Moreover, it also allows to sensibly reducing the level of organizational 
Table 2. Levels of organizational compatibility/co-operability (Clark \& Jones, 1999)

\begin{tabular}{|c|c|c|c|c|}
\hline \multirow{2}{*}{$\begin{array}{l}\text { Levels of co- } \\
\text { operation } \\
\text { cooperability }\end{array}$} & Preparedness & Understanding & Command Style & Ethos \\
\cline { 2 - 5 } & $\begin{array}{c}\text { Complete, normal day-to- } \\
\text { day working }\end{array}$ & Shared & Homogeneous & Uniform \\
\hline Unified & Detailed doctrine and \\
experience in using it & $\begin{array}{c}\text { Shared communications } \\
\text { and shared knowledge }\end{array}$ & $\begin{array}{c}\text { One chain of command } \\
\text { and interaction with home } \\
\text { organizations }\end{array}$ & $\begin{array}{c}\text { Shared ethos but with } \\
\text { influence from home } \\
\text { organizations }\end{array}$ \\
\hline Collaborative & $\begin{array}{c}\text { General doctrine in place } \\
\text { and some experience }\end{array}$ & $\begin{array}{c}\text { Shared communications } \\
\text { and shared knowledge } \\
\text { about specific topics }\end{array}$ & $\begin{array}{c}\text { Separate reporting lines } \\
\text { of responsibility overlaid } \\
\text { with a single command } \\
\text { chain }\end{array}$ & $\begin{array}{c}\text { Shared purpose; } \\
\text { goals, value system } \\
\text { significantly } \\
\text { influenced by home } \\
\text { organizations }\end{array}$ \\
\hline Ad hoc & General guidelines & $\begin{array}{c}\text { Electronic } \\
\text { communications and } \\
\text { shared information }\end{array}$ & $\begin{array}{c}\text { Separate reporting lines of } \\
\text { responsibility }\end{array}$ & \begin{tabular}{c} 
Shared purpose \\
\hline Independent
\end{tabular} \\
\hline
\end{tabular}

heterogeneity among them, so that they can be perceived as part of a single and highly connected system of European government organizations. Finally, by basing inter-organizational cooperation on both interoperability and co-operability, the integration of different public sector organizations from different Member States can be achieved even without forcing them to conform to a unique organizational model. This allows safeguarding the autonomy of each organization participating in the cross-boundary services delivery, which Pardo, Gil-Garcia and Burke (2006) identify as one of the condition that can improve the effectiveness of inter-organizational cooperation.

\section{THE WEB AS A COOPERATION PLATFORM}

\section{Social Computing and Cooperation Services for Inter- Organizational Trust Building}

The conditions that define co-operability are quite difficult to satisfy, especially when the higher levels of co-operability are considered. Indeed, they are not the kind of conditions that can be satisfied simply by signing inter-organizational agreements. Rather they require different organizations to enter complex processes of mutual adjustment that, in the end, will reduce their organizational heterogeneity and allow them to function together essentially as a single organization.

The process through which different organizations can achieve higher levels of co-operability can be considered as a learning process, in which different organizations engage in a series of iterative and interactive learning cycles over time, typically characterized by greater and greater trust and adaptive flexibility, as well as the willingness to make increasing and irreversible commitments.

By discussing the formation of strategic alliances, Doz (1996) describes such a learning process as in Figure 1.

According to this description of the evolution of inter-organizational cooperation, the cooperation can be activated through the definition of an agreement (for instance the interoperability agreements defined by the EIF) stating the initial conditions for the cooperation. Once the cooperation has been activated, different organizations can start adapting to each other by learning from 
Figure 1. The evolution of inter-organizational cooperation (Doz, 1996)

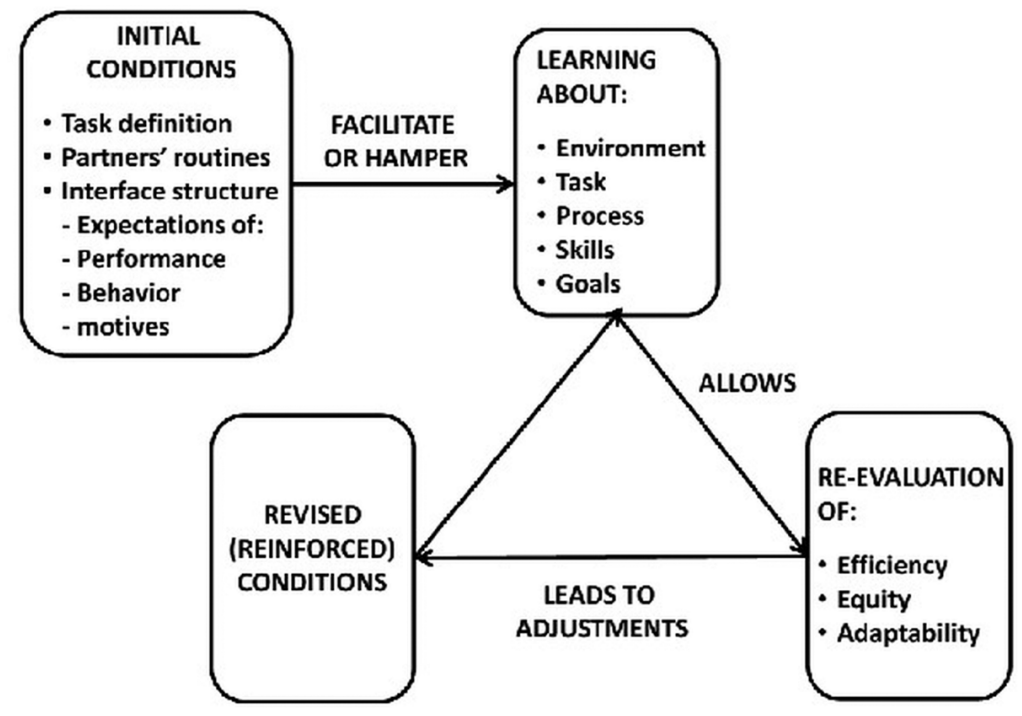

their mutual interactions. Through the iteration of the learning cycles over time, trust relationships among different organizations can be established and reinforced, which is the basis for the mutual adjustment and trust reinforcing processes that can lead to co-operability.

(Castelnovo, 2012) argues that sharing a cooperation environment and a cooperation platform can support the learning process represented in Figure 1. The cooperation environment can be conceived of as a set of conditions that, based on a shared reference model, specify the interoperability requirements different organizations should satisfy at the strategic, the organizational, the operative and the technological level in order to cooperate. These requirements are those that can be explicitly stated in the cooperation agreement. The cooperation platform can be conceived of as a set of specific tools and services that support interorganizational cooperation (Camarinha-Matos \& Afsarmanesh, 2003; Ollus, 2005; 2007). Among the services and tools that the cooperation platform should provide, particularly relevant are those that enable directinteractions among people belonging to different organizations, not necessarily limited to the interactions required for the execution of inter-organizational workflows.
Interpersonal relationships are fundamental for establishing, maintaining and strengthening trust at both the inter-personal and the interorganizational level (Kramer, 1999). This makes the Social Computing and Cooperation Services (SC\&CSs) and tools made available by the socalled Web 2.0 particularly useful to support the learning process leading to co-operability. Indeed, social computing and cooperation services can be considered as a set of applications that enable people to efficiently interact with other people, as well as to share contents and data through the Web (Parameswaran \& Whinston, 2007; Young, 2007; Warr, 2008). Whereas publicly available SC\&CSs are already widely diffused for private use (Pascu, 2008), their adoption and use by enterprises and government organizations is still quite limited, although it is widely expected that the adoption of SC\&CSs would have a high positive impact on both enterprises and government organizations (Bughin, Chui \& Miller, 2009; Doculals, 2010; Osimo, 2008).

Table 3 gives a schematic overview of some of the more common SC\&CSs, grouped with respect to the four basic functionalities provided by social computing: messaging, collaboration, broadcasting and knowledge building. Some of 
Table 3. Social Computing and Cooperation services (based on (Doculabs, 2010))

\begin{tabular}{|l|l|l|l|}
\hline & Already Widely Used & Increasingly Adopted & Rarely Used \\
\hline Messaging & E-mail & $\begin{array}{l}\text { Instant messaging } \\
\text { Presence detection } \\
\text { Unified telephony }\end{array}$ & \\
\hline Collaboration & $\begin{array}{l}\text { File/document sharing } \\
\text { Portal } \\
\text { Calendaring }\end{array}$ & $\begin{array}{l}\text { Discussion forum } \\
\text { Shared whiteboard } \\
\text { Shared workspace }\end{array}$ & $\begin{array}{l}\text { Audio broadcasting } \\
\text { Blog } \\
\text { Content syndication }\end{array}$ \\
\hline Broadcasting & Web conferencing & Wiki & $\begin{array}{l}\text { Micro-blogging } \\
\text { Video broadcasting }\end{array}$ \\
\hline Knowledge building & & $\begin{array}{l}\text { Polling } \\
\text { Community building } \\
\text { Expertise management } \\
\text { Social filtering } \\
\text { Knowledge market }\end{array}$ \\
\hline
\end{tabular}

these services are already widely used by organizations, both for internal purposes and for customer related purposes. Others are being increasingly adopted by organizations; yet others are still quite rarely used, although the greatest value is expected from their adoption.

The term "Enterprise 2.0" refers to the use of SC\&CSs by enterprises, as well as to their embracing of the collaborative philosophy of Web 2.0 (McAfee, 2006; 2009). By analogy, the term Government 2.0 refers to the use of SC\&CSs by government organizations (Osimo, 2008; Mergel, Schweik \& Fountain, 2009; Dixon, 2010); sometimes it is also used to refer to the next step of e-Government towards more participatory arrangements (Baumgarten \& Chui, 2009).

As enterprises, also government organizations can adopt SC\&CSs either to support interactions among organization members (internal focus) or for facing citizens, partners and suppliers (external focus). The use of SC\&CSs described in this chapter is intermediate between the two. The use of SC\&CSs to establish and enforce relationships among different (public administration) organizations that cooperate for the delivery of services has an external focus (since the focus is on inter-organizational relationships). However, this use of SC\&CSs concerns the strengthening of the relationships among the members of an inter-organizational network as the condition that could enable them to achieve higher levels of cooperability. Used in this sense SC\&CSs have an internal focus. From this point of view it can be said that, integrated within the cooperation platform, SC\&CSs are used with a "network focus."

The use of SC\&CSs to establish and reinforce the relationships among the members of different organizations exploits the SC\&CSs capacity of supporting the establishment and the reinforcement of different types of ties between individuals. Following McAfee's bull's eye metaphor (McAfee, 2009), the different types of ties in which an individual can be involved can be represented as in Figure 2.

Strong ties are those ties that bind people that are used to work together; people that work together only occasionally are bound by weak ties, whereas the potential ties are those ties that could be established if only there was the opportunity. McAfee (2009) makes a connection between this classification of ties and different SC\&CSs. Thus, for instance, he claims that a tool like Wiki is useful for people with strong ties working closely together, whereas Blogs can be seen as a way of both nurturing and creating new weak ties, and social networking is particularly useful for creating new potential ties that can possibly evolve in weak ties (or even in strong ties). 
Figure 2. Types of ties (McAfee, 2009)

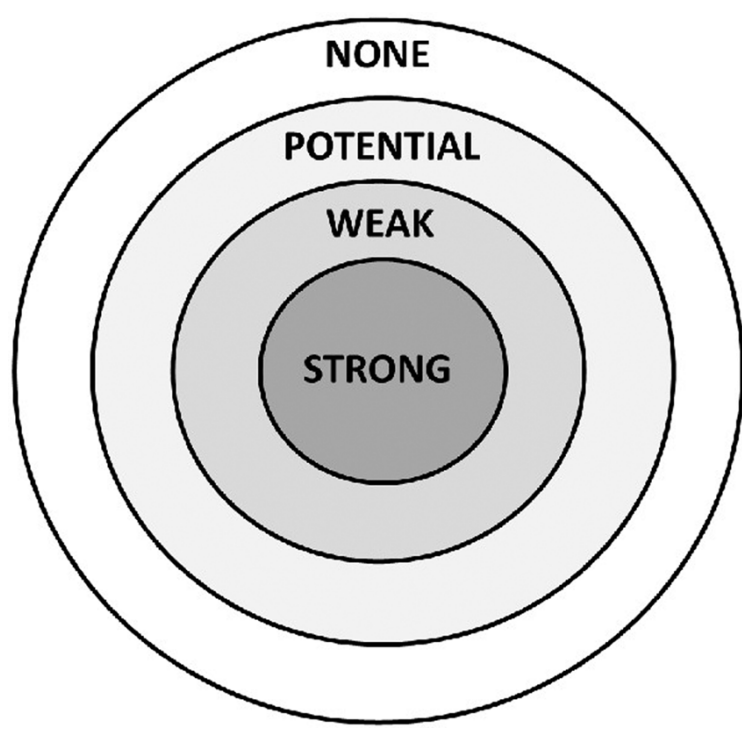

McAfee's classification of interpersonal ties can be used also to describe different types of relationships among people belonging to different organizations involved in an inter-organizational cooperation. The strong inter-organizational ties are those ties that bind people that, while belonging to different organizations, nevertheless work together on a day-to-day basis. The weak interorganizational ties are those ties that bind people belonging to different organizations that interact only occasionally. Finally, all the employees of the organizations involved in the cooperation are linked by potential ties that could evolve into weak ties (or even into strong ties) if the cooperation will widen the range of the shared resources and activities.

The establishment of strong ties cannot be determined by the use of technological tools alone; indeed, strong ties require a level of acquaintance and trust that only working shoulder to shoulder can determine. However, the use of SC\&CSs allows the systematic sharing of knowledge and the exploitation of collective intelligence; besides making the cooperation more efficient and effective, this can help the members of different organizations to achieve and maintain a shared value system, a sharing of the goals, and a common understanding, as required by the higher levels of co-operability.

In the case of weak and potential ties, SC\&CSs can play a more direct role in establishing, maintaining and strengthening interpersonal links. Tools like blogs and social networks can help establishing new interpersonal relations and allow the sharing of information and knowledge also among people loosely tied, as people belonging to very large organizations usually are (but the same holds for people belonging to different organizations as well) (Dimicco et al., 2009).

The fundamental role of weak ties to allow knowledge workers to access non-redundant information is well known. The role of weak ties for reducing organizational heterogeneity among different organizations is much less studied. However, data are available that show how the use of SC\&CSs supporting the establishment of week ties can determine "social" benefits including the sharing of a common organizational culture and identity among people geographically dispersed (Jackson, Yates \& Orlikowski, 2007; Richter \& Riemer, 2009). This can help creating an environment conducive to trust building, which is a fundamental condition for co-operability.

SC\&CSs and tools are increasingly been adopted by enterprises and government organizations and there is a growing interest in both Enterprise 2.0 and Government 2.0. However, the adoption rate of SC\&CSs by enterprises and government organizations is still quite low. The 2012 AIIM's survey (AIIM, 2012) on the adoption and use of social computing tools and techniques by enterprises (including both central and local government organizations) reports that in only $50 \%$ of the organizations that responded to the survey employees are encouraged to use SC\&CSs in relation to their job. Moreover, only $37 \%$ of respondents think that SC\&CSs will be in regular use across the whole enterprise in the next 2 years. 
The data concerning government organizations are even worse; $42 \%$ of government organizations restrict use of social tools completely (only $16 \%$ of enterprises do the same). Government organizations delivering services to citizens are three times more likely (29\%) to have taken disciplinary action with staff relating to social activity than other organizations (11\%). $44 \%$ of Government organizations delivering services to business actively discourage employees from using SC\&CSs for their job (the average figure for this in enterprises is $19 \%$ ).

The gap between the expected and the actual data concerning the adoption and use of SC\&CSs in enterprises mainly depends on some well-known risks that enterprises still perceive as related to the adoption of SC\&CSs. Such risks concern inappropriate behavior and content, inaccurate information, embarrassing content, non-compliance with laws, regulations, intellectual property or policies (McAfee, 2009). Besides these, Dawson (2009) identifies further risks concerning reduced staff productivity, IT security and loosing of control. However, despite all these well-known risk, AIIM (2012) reports that at least $50 \%$ of the surveyed organizations feel that integrating SC\&CSs to all types of business process would be very or extremely valuable. This makes the identification of the right strategy for the introduction of SC\&CSs the critical step for assuring their adoption and use.

Raeth et al. (2009) observes that despite their potential to transform workflows and organizations, SC\&CSs are more likely to be implemented as tools for complementing existing work practices and structures. Moreover, they also observe that "unlike process-oriented enterprise systems for which use is often mandated, Web 2.0 systems, with their emphasis on supporting individual and group's idiosyncratic communication and collaboration activities, are more likely to be treated either officially or practically voluntary" (Raeth et al., 2009, p. 1). Instead, Chui, Miller and Roberts (2009) identify the integration of SC\&CSs within existing workflows as a critical success factor for the adoption of SC\&CSs. According to them, this avoids the risk that employees perceive the use of SC\&CSs just as another "to do" on an already crowded list of tasks. Bughin, Chui and Miller (2009) found that successful companies not only tightly integrate Web 2.0 technologies with the workflows of their employees but also create a "networked company," linking themselves with customers and suppliers using Web 2.0 tools (Bughin, Chui, \& Miller, 2009, p. 1).

\section{SOCIAL COMPUTING AND COOPERATION SERVICES FOR SUPPORTING INTER- ORGANIZATIONAL WORKFLOWS}

In this section of the chapter, I will describe a possible use of SC\&CSs that is in line with the observations above. More specifically, I will consider the possibility of using SC\&CSs to support the execution of the inter-organizational workflows related to the procedures for starting, transforming or closing a business in Italy. This case is particularly interesting since it involves the activity of One Stop Shop for Production Activities in Italy (SUAP - Sportello Unico per le Attività Produttive), which is a typical example of connected e-Government. Moreover, under the Italian legislation in force, the SUAPs have competence on most of the 10 cross-border services related to business and start-up considered in (EC, 2013). From this point of view, the case that will be discussed in the following pages can be considered as related to the cross-border delivery of services through connected government.

One-Stop Shop for Production Activities (SUAP) as the single point of access to services and information for business offered by different public authorities has been established in Italy since the late ' 90 s as part of the policies for reducing the administrative burdens on enterprises. According to the Italian law, each municipality must establish its own SUAP by choosing among establishing it 
individually, sharing it with other municipalities throughinter-municipal cooperation or delegating it to the local Chamber of Commerce.

Under the legislation currently in force, a new business can be started up simply through a communication (Segnalazione Certificata di Inizio Attività - SCIA, Certified Communication of the Start of the Activity) submitted online to the SUAP through the national portal www. impresainungiorno.it. This portal acts as the Point of Single Contact (PSC), as required by the so-called Service Directive issued in 2006 by the European Union. The online procedure is such that it guarantees that the SCIA contains all the required information and that all the required documents have been attached (if the communication is incomplete it is rejected). A SCIA that has been checked for completeness is registered to the system that automatically sends a receipt to the applicant. Upon receiving this receipt, an entrepreneur can start a new business.

Upon registering the SCIA, the SUAP has to operate all the required controls within an interval of time defined by the law (60 days). If any of the controls detects any inadequacy, then the business can be stopped (either temporally until the inadequacy will be removed or definitively, if the inadequacy cannot be removed), otherwise it can operate without requiring any further authorizations.

The new legislation did not reduce the number of public agencies and authorities having competences concerning starting, transforming or closing a business, which besides municipalities includes Fire Departments, Public Health agencies, Regional and Provincial governments, and other public agencies depending on the type of the business. This means that the controls that have to be operated may involve many different public agencies. However, given the lack of resources affecting them, those agencies could have difficulties in promptly operating all the required ex-post controls on all the SCIAs submitted to the SUAP.
In such a situation, the only way to satisfy the requirements stated by the law is by identifying what controls really need to be operated, based on a careful evaluation of the potential risks each SCIA submitted to the SUAP could entail. Since each agency's evaluation can have consequences on the result of the processing of a SCIA, thus affecting the other authorities' activities and decisions, it is necessary for all the actors involved to share both their evaluation of the potential risks it could entail and their decisions whether or not to perform some controls on it. This requires the SUAP to implement an efficient and effective system for coordinating decisions involving many different public bodies. The decision whether or not to perform controls on a given SCIA could entail some form of risk. Hence, the SUAP should implement an inter-organizational risk management system, i.e. a system whose goal is "to more effectively allow organizations to share information and perform necessary activities with regard to risk management that may affect their collective behavior" (Meyers, 2006, p. 6).

The Team Risk Management (TRM) approach described in (Higuera etal., 1994) defines methods and tools that can be used to manage risks at the inter-organizational level. In the TRM approach, three types of risk management processes are considered:

- The Baseline Risk Assessment: Which is an intra-organizational process executed independently by each organization to individually identify the risks associated with their respective organizations.

- The Team Review Process: Which is an inter-organizational process conducted jointly by the organizations involved to share and jointly evaluate the most important risks they individually identified.

- A Set of Continuous Processes: Implemented at both the intra and the inter-organizational level, which comprise a cyclic set of activities by means of 
which each organization involved manages risks at the intra-organizational level and, through a repeated execution of the team review process, at the inter-organizational level as well.

Figure 3 below shows how TRM can be integrated within the SUAP workflow. After registering a SCIA submitted to it through the PSC, the SUAP sends the relevant documentation to all the agencies having competences on it. Upon receiving the documents, the agencies individually perform the baseline risk assessment process, with the aim of identifying all the potential risks that SCIA could entail. Besides evaluating the potential risks involved, during this phase each partner can also plan the execution of its control activities on that SCIA. The team review allows the partners to jointly evaluate the SCIA based on the potential risks each one of them identified

Figure 3. Integration of TRM within the SUAP's workflow

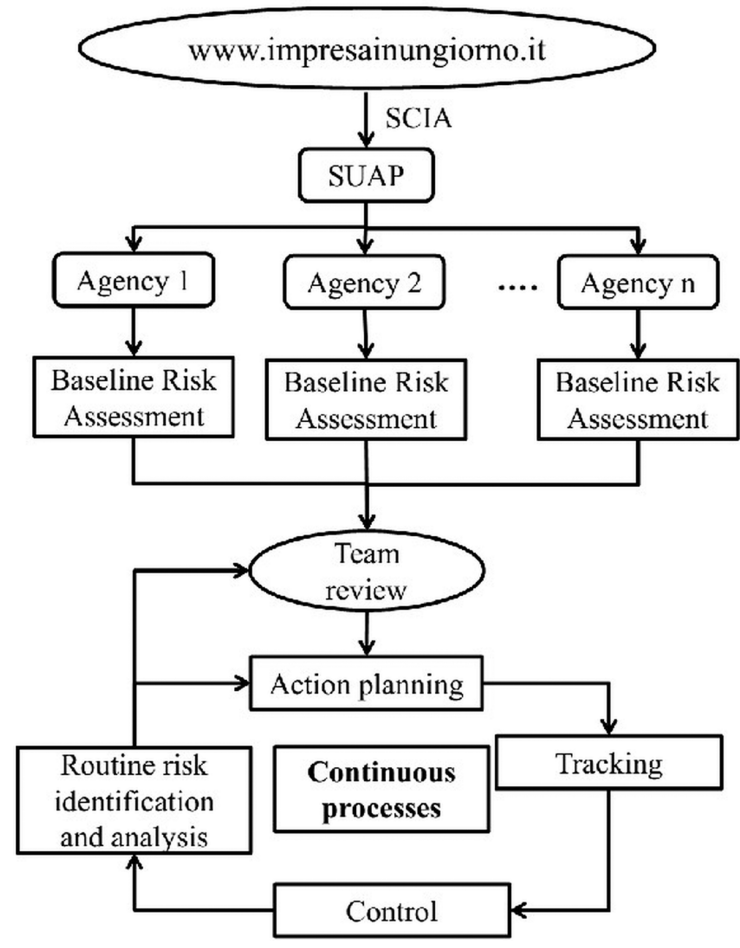

individually, thus arriving at a shared risk evaluation. Such an evaluation forms the basis for jointly deciding whether to perform the required controls on that SCIA.

As observed above, the SUAP's workflow is constrained by strict temporal requirements since all the possible controls should be made within 60 days from the online submission of the SCIA to the PSC. This raises two questions: (i) what risk management processes can be made more efficient and effective in order to conclude the controls within the terms fixed by law, and how this can be done; (ii) what technologies and tools can be used to make those processes more effective and efficient, both at the intra-organizational and at the inter-organizational level.

Castelnovo (2011) describes some requirements that should be satisfied in order to make both the Baseline Risk Assessment and the Team Review processes more efficient and effective. Table 4 summarizes such requirements.

Both the Baseline Risk Assessment and the Team Review essentially amount to group decision processes, i.e. a processes in which different people (possibly belonging to different organizations) "work together to analyze and prioritize alternative solutions to problems and choose one alternative through extensive communication, analysis, deliberation, and negotiation" (Turban, Liang \& Wu, 2011, p. 138).

Based on a comparison of different frameworks for group decision making, Turban, Liang and $\mathrm{Wu}$ (2011) identify the following four main activities for group decision making:

- Intelligence: Which amounts to information gathering and sharing for the purpose of problem identification and determining its importance.

- Design: Which amounts to finding alternative solutions and analyzing them.

- Choice: Which amounts to selecting an effective course of action. 
Table 4. Requirements for the Baseline Risk assessment and the Team Review

\begin{tabular}{|l|l|}
\hline \multirow{3}{*}{$\begin{array}{l}\text { Baseline Risk } \\
\text { Team Review }\end{array}$} & A1. Identify the people to be involved in the risk assessment, whatever organization they belong to. \\
\cline { 2 - 3 } & A2. Promptly inform them that their advices are needed to evaluate a SCIA. \\
\cline { 2 - 3 } & $\begin{array}{l}\text { A3. Support their risk assessment activity by giving them access to information concerning how analogous } \\
\text { cases have already been treated previously. }\end{array}$ \\
\hline & $\begin{array}{l}\text { B1. Allow all the involved organizations to decide and share their decision without requiring them to } \\
\text { participate in face-to-face meetings. }\end{array}$ \\
\hline $\begin{array}{l}\text { B2. Let all the involved organizations be promptly informed of the possible occurrence of secondary risks } \\
\text { (risks rising as a consequence of the implementation the risk handling actions), wherever they have be } \\
\text { detected. }\end{array}$ & $\begin{array}{l}\text { B3. Promptly inform all the managers that have to implement the risk handling actions agreed on (whatever } \\
\text { organization they belong to) of what they are expected to do and when. }\end{array}$ \\
\cline { 2 - 3 } & $\begin{array}{l}\text { B4. Let all the managers (whatever organization they belong to) intervene in the decision making process to } \\
\text { contribute to the best timing for the execution of the risk handling actions agreed on, also considering the } \\
\text { priorities already defined by the organizations they belong to. }\end{array}$ \\
\hline
\end{tabular}

- Implementation: Which amounts to managing the process and implementing the solution.

All these activities can be made more efficient and effective by using Collaboration 2.0 tools, which amounts to the use of Web 2.0-based social software services and tools (i.e. SC\&CSs) to facilitate intra and inter-organizational collaboration (Coleman \& Levine, 2008; Sari et al., 2008). Table 5 summarizes the use of SC\&CSs to support group decision-making (Turban, Liang \& Wu, 2011, p. 144).

By considering the inter-organizational risk management processes described above as group decision making processes, the same Collaboration 2.0 services and tools (SC\&CSs) Turban, Liang and $\mathrm{Wu}$ suggest to use to support the activities reported in Table 5, can be used to support the SUAP's inter-organizational workflow as well.

The requirement A1 in table 4 concerns the identification of the people (domain experts) to involve in the baseline risk assessment (and in the routine risk identification and analysis, as well), which can be considered as a case of expertise management. A way to satisfy the requirement A1 is by requiring all the organizations involved in the SUAP's activity to associate an expertise profile to each of their knowledge workers (or at least to those directly involved in the execution of the SUAP's workflow). This would allow the manager responsible for the SUAP to find the competencies required for the processing of a given SCIA simply by browsing (either automatically or manually) the expertise profiles. This can be done by transforming the usual "directory of people" from the "yellow pages" model to a social network model, analogous to the IBM's "Blue Pages" described in (Richter \& Riemer, 2009). Besides making the search of experts easier, representing expertise through social network profiles also allows the possibility of making the expertise description more reliable by means of social filtering mechanisms that can be used to further qualify the level of expertise of registered experts (Damianos et al., 2007; Braun, Kunzmann \& Schmidt, 2008).

By resorting to this solution, upon receiving a SCIA the SUAP can prompt all the agencies involved to activate the concurrent execution of their baseline risk assessment processes through the following steps:

- Identify all the agencies that need to be involved in the processing of that SCIA. 
Table 5. Collaboration 2.0 tools supporting group decision making

\begin{tabular}{|c|c|c|}
\hline & Group Decision Making Process Tasks & Collaboration 2.0 tools \\
\hline \multirow[t]{4}{*}{ Intelligence } & Problem Identification & BlogBlogs, IM, Polls (voting) \\
\hline & Information finding/sharing & RSS feeds, blogblogs, Twitter \\
\hline & Soliciting expert's opinion & $\begin{array}{l}\text { Social networks answering function } \\
\text { Enterprise social bookmarking }\end{array}$ \\
\hline & Prioritize problems (importance) & $\begin{array}{l}\text { Voting, blogblogs, IM, discussion groups } \\
\text { (forums), chat room }\end{array}$ \\
\hline \multirow[t]{6}{*}{ Design } & Search for alternative solutions & Search tools, expert/answering \\
\hline & Idea generation—brainstorming & Discussion groups, blogblogs, IM, chat room \\
\hline & Experts' opinions & Answer function, IM, Twitter \\
\hline & Organize alternatives & WikiWiki \\
\hline & Identify criteria of choice & WikiWiki, blog, IM, discussion groups \\
\hline & Prioritize criteria of choice (importance) & Discussion groups, voting, IM, chat room \\
\hline \multirow[t]{2}{*}{ Choice } & Analysis (Forecasting, risk, comparisons) & $\begin{array}{l}\text { Collaborative decision making (Social networking plus } \\
\text { Business Intelligence analysis) }\end{array}$ \\
\hline & Selection of an alternative & Polling, discussion groups, IM \\
\hline \multirow[t]{4}{*}{ Implementation } & Meeting management & Twitter, RSS feeds \\
\hline & Project management & Presence awareness, Twitter, blog \\
\hline & Report writing & WikiWiki \\
\hline & Training (if needed) & Virtual worlds \\
\hline
\end{tabular}

- Identify what are the competences required to properly assess the potential risks involved in that SCIA.

- $\quad$ Search the network (by means of a social network search engine) for people with the required competences.

- $\quad$ Send the relevant documentation directly to the people identified in the previous step, irrespective of the organization they belong to (this step accounts for the requirement $\mathrm{A} 2$ in table 4 as well).

A different approach to searching the experts (that could also be integrated in the searching of profiles approach) is by means of microblogging. People normally use microblog to provide to others updates on their activities, observations and interesting content. However, based on data concerning the IBM's microblogging application BlueTwit, Ehrich and Shami (2010) found that workplace employees are mostly using the tool to post information, engage in brief directed conversation and asking help from colleagues. This suggests the possibility of using a microblog post to identify the people to involve in the baseline risk assessment; this could be done in the form of a request for help to which people with the required competences answer. By means of the same post, these people get also informed of the fact that their advices are needed, thus satisfying the requirement $\mathrm{A} 2$ as well. A further alternative is the use of automatically generated RSS feeds instead of microblogs posted by people allocated to the SUAP.

Microblogs can be used in all the situations in which the people involved need to be promptly informed of the occurrence of potentially critical events, as in the case of a partner's detection of a secondary risk arising during the execution of the risk handling actions he is in charge of. In this 
case, as he detects the secondary risk, a partner can post a microblog informing of this, almost in real time, all the other partners that will thus be prepared to define and share the most adequate measures to cope with the new situation. Hence, by resorting to microblogging also the requirements B2 and B3 can be satisfied.

Blogs represent powerful tools for sharing expertise, improving cooperation and enabling business intelligence creation (Andrus, 2005; Kolari et al. 2007). In the case we are considering, the use of blogs satisfies also the requirements A4, B1 and B4. Upon receiving a SCIA, the manager responsible for the functioning of the SUAP can initiate a blog devoted to its risk assessment. The managers responsible for risk assessment (both the baseline risk assessment and the routine risk identification and analysis) within the organizations involved in the processing of that SCIA can then post comments on that blog. In this way, all the people involved in the risk evaluation can share their evaluation of: (i) the potential risks involved (for their organizations); (ii) the need of performing the ex-post controls on that SCIA; and (iii) the timing for the execution of the controls. This allows:

- The definition of a shared risk profile for the SCIA under processing (requirement A4).

- A shared decision concerning whether to perform the controls, and when (requirement B1), possibly also by resorting to polling mechanisms that can be integrated quite easily in a blog (Rodriguez et al., 2007).

- A shared planning of the execution of all the ex-post controls (whatever organization is responsible for each control activity), compatible with the other activities each partner has to perform as part of his normal activity (requirement B4).
Blogs can be used to share information and decisions both at the inter-organizational and at the intra-organizational level. In the latter case, the use of blogs would allow the manager responsible for the internal risk assessment to collect information and advices that could be useful for a sound risk assessment from people within the organization (whatever unit they belong to).

Risk assessment, and risk treatment as well, can be more efficient and effective when information concerning previous experiences can be used to derive useful insights on how to treat the case at hand. One way to do this is by allowing the use of tools that enable groups to jointly create and share content; Wikis are typical collaborative tools that can be used to this end, even in critical contexts (Wagner, 2004; Andrus 2005). In the processing of a SCIA, blogs can be used to make a shared risk assessment and a shared risk treatment strategy emerge from the collaborative effort of people belonging to different organizations (as well as to different units within the same organization). Wikis, instead, can be used to document the whole risk assessment and risk treatment processes for that SCIA. The intrinsic collaborative nature of the Wiki enables documents to be written collectively by all the people involved in the risk management and the risk treatment processes (whatever organization they belong to), thus allowing a more structured, complete, reliable and useful documentation of the way a SCIA has been treated. Moreover, the possibility of using both content tags and meta-information tags and links to organize the content of Blogs and Wiki pages makes it particularly easier to find the information needed (Kolari et al., 2007). This allows a more efficient use of past experiences in both the risk assessment and the risk treatment processes. From this point of view, by using Wikis to document the risk management processes also the requirement A3 in table 4 above can be satisfied. 


\section{CONCLUSION}

The use of Social Computing and Cooperation services and tools (SC\&CSs) by organizations, as well as their embracing of the collaborative philosophy of Web 2.0, to improve both internal and external relationships is continuously increasing and there is a general expectation that this will determine a deep transformation in the way organizations will work in the interconnected world. Besides enterprises, also government organizations are increasingly adopting SC\&CSs with the aim of making their processes more transparent, fostering citizens' participation and promoting collaboration and cooperation among government agencies.

Inter-agencies cooperation lies at the basis of Connected Government whose aim is to enable government organizations to connect seamlessly across functions, agencies, and jurisdictions to deliver effective and efficient services to citizens and businesses. In the countries of the European Union, this objective concerns the delivery of services within each Member State and the delivery of cross-border services as well. Indeed, the possibility for European citizens and businesses of accessing cross-border (and cross-boundary) services (either delivered completely online or through some form of face-to-face/paper based interaction) represents a fundamental step toward the strengthening of the perception of living and working in a Single Market.

Connected Government is difficult to achieve in the European Union due to the high organizational heterogeneity among government organizations, both at the national and at the cross-border level. Without reducing organizational heterogeneity among government organizations from different Member States, it is very unlikely that their interactions with European public administrations could strengthen the European citizens' perception of living and working in a Single Market.

Interoperability allows different organizations to interact through the exchange of information.
However, interoperability by itself cannot reduce organizational heterogeneity since it also depends on the social dimension of organizations, which includes "human factors" such as feelings, motivation, trust, communication, culture, personal relationships, goals, values and commitment. Besides possibly making European citizens experience striking differences when interacting with public administrations in different Member States, all the above-mentioned elements can affect the effectiveness of inter-organizational cross-boundary cooperation and the delivery of seamless cross-boundary services as well.

Organizational heterogeneity can be reduced through co-operability, which is a form of nontechnical interoperability aiming at the successful bridging of differences in doctrine, organization, concepts of operation, and culture so that different organizations can function together essentially as a single organization with no loss in effectiveness. The process that can lead different organizations to achieve higher levels of co-operability can be considered as a learning process in which different organizations engage in a series of iterative and interactive learning cycles over time, typically characterized by greater and greater trust and adaptive flexibility, as well as the willingness to make increasing and irreversible commitments. In the chapter, I argued that the use of SC\&CSs to support the interactions among different public administrations could make this learning process more efficient and effective. This is due to the role SC\&CSs can play in the establishment, maintenance and strengthening of inter-personal relationships, both within and across the organizational boundaries, which is fundamental for every trust-building process.

Many barriers have to be overcome in order to allow an effective use of SC\&CSs within organizations (Bughin, 2008). A detailed discussion of those barriers is outside the scope of this chapter; however, there is at least one point that deserves some attention here. The take up of SC\&CSs by employees is not spontaneous. (AA.VV., 2010) 
reports that companies quote employees resistance as the single biggest barrier to adoption; McAfee (2009) has reached the same conclusion based on his interviews with lead companies. This point is crucial for the use of SC\&CSs suggested in this chapter. Actually, both the use of SC\&CSs to support the learning process that can lead to cooperability, as the basic condition for connected government, and the use of SC\&CSs to make the SUAP's workflow more efficient and effective heavily rely on the employees' willingness to collaborate, within and across organizational boundaries.

However, this problem concerns collaboration in itself rather than the adoption and use of services and tools that can make collaboration easier, as SC\&CSs are. People are the critical ingredient in any collaboration; no benefit can be realized without people being willing to trust and share both the content and themselves (Coleman \& Levine, 2008). The success of any process based on collaboration depends on the ability to address people, process, and technology issues simultaneously with the heaviest focus on people. Coleman and Levine (2008, p. 24) observe that usually $80 \%$ (or more) of the effort in collaboration goes into the development of the enabling technologies instead, whereas only $20 \%$ (or less) is focused on the relationships or interactions between people. This suggests a first indication of what should be done to overcome the barriers that could limit the use of SC\&CSs: invest more on people and on their relationships than on technology, which is just an enabling element whose value is in its capacity of supporting people in the way they work, without imposing further burdens on them.

This leads to another important success factor for the adoption and use of SC\&CSs. The best practices show that the highest chances of success depend on the integration of the new tools within existing workflows and on their application to the core activities of the organization. The use of SC\&CSs described in this chapter concerns the procedures for starting, transforming or closing a business in Italy. The efficiency and effectiveness of these procedures, implemented by the One Stop Shop for Production Activities, are critical for the reduction of the administrative burdens on enterprises, which represents a strategic policy objective for the Italian Public Administration. From this point of view, the use of SC\&CSs described in the chapter satisfies the success condition above for the adoption of SC\&CSs by organizations.

Under the legislation in force, the procedures for starting, transforming or closing a business in Italy require the execution of inter-organizational workflows in which different public agencies have to perform a coordinated set of activities, according to the competencies set to them by laws and regulations. All these activities are tied together through informal and formal communication processes that enhance the cooperative interactions and trust between the people and the organizations involved.

Communication (both formal and informal) represents a fundamental condition for enabling effective cooperation. On the one hand, through communication all the actors involved in the execution of inter-organizational workflows can build and reinforce a shared vision, create a sense of collective ownership and responsibility, enhance inter-organizational trust, which can make the cooperation more effective and easier to manage. On the other hand, at the operative level, communication enhances the interactions among all the actors involved, both at the intraorganizational and at the inter-organizational level, and allows information and knowledge to be shared among them, which makes the execution of inter-organizational workflows more efficient and effective.

Fundamental as they are for effective cooperation, communication and knowledge sharing are not so easy to manage at the inter-organizational level. However, as Coleman and Levin (2008, p. 9) point out, "when you couple technology and process with interpersonal styles, awareness, communication tools, and some conversational 
models that support 'sustainable collaboration', you have a winning combination." Social Computing and Cooperation services provide such a winning combination that, as shown in the chapter, can be exploited to enhance inter-organizational cooperation, to allow the seamless delivery of cross-administration/sectorial/borderservices and to pursue the objective of Connected Government.

\section{REFERENCES}

AA.VV. (2010). Enterprise 2.0 study - D4 Final report. European Commission.

AIIM. (2012). Social in the Flow-transforming processes and sharing knowledge. AIIM Industry Watch.

Alberts, D. S., Huber, R. K., \& Moffat, J. (2010). NATO NEC C2 maturity model. U.S. Department of Defence.

Alter, S. (2006). The Work System Method: Connecting People, Processes and IT for Business Results. Larkspur, CA: Work System Press.

Andrus, D. C. (2005). The Wiki and the Blog: Toward a Complex Adaptive Intelligence. Central Intelligence Agency.

Bannister, F. (2002). Citizen Centricity: A Model of IS Value in Public Administration. Electronic Journal of Information Systems Evaluation, 5(2).

Braun, S., Kunzmann, C., \& Schmidt, A. (2008). People Tagging \& Ontology Maturing: Towards Collaborative Competence Management. In Proceedings of 8th International Conference on the Design of Cooperative Systems COOP '08. Carry-le-Rouet, France: COOP.
Bughin, J. (2008). The rise of enterprise 2.0. Journal of Direct. Data and Digital Marketing Practice, 9, 251-259. doi:10.1057/palgrave. dddmp.4350100

Bughin, J., Chui, M., \& Miller, A. (2009). How companies are benefiting from Web 2.0 - McKinsey Global Survey Results. The McKinsey Quarterly.

Camarinha-Matos, L. M., \& Afsarmanesh, H. (2003). Elements of a base VE infrastructure. Computers in Industry, 51,139-163. doi:10.1016/ S0166-3615(03)00033-2

Castelnovo, W. (2011). Social Computing Tools for Inter-organizational Risk Management. In Proceedings of the 5th European Conference on Information Management Evaluation. ECIME.

Castelnovo, W. (2012). An Architecture Driven Methodology for Transforming from Fragmented to Connected Government: A Case of a Local Government in Italy. In Enterprise Architecture for Connected E-Government: Practices and Innovations. Hershey, PA: IGI Global. doi:10.4018/9781-4666-1824-4.ch015

Castelnovo, W. (2013). A Stakeholder Based Approach to Public Value. In Proceedings of the $13^{\text {th }}$ European Conference on E-Government. ACPI.

Castelnovo, W., \& Simonetta, M. (2007). The Evaluation of E-Government projects for Small Local Government Organisations. Electronic Journal of E-Government, 5(1).

CEMR. (2011). EU Subnational Government - 2010 Key Figures, 2011/2012 Ed. Council of European Municipalities and Regions. Retrieved June 22, 2013, from http://www.ccre.org/docs/ Nuancier2011Web.EN.pdf 
Chui, M., Miller, A., \& Roberts, R. P. (2009). Six ways to make Web 2.0 work. The McKinsey Quarterly.

Clark, T., \& Jones, R. (1999). Organisational Interoperability Maturity Model for C2. In Proceedings of the Command and Control Research and Tecnology Symposium. Retrieved June 22, 2013, from http://www.dodccrp.org/events/1999_ CCRTS/pdf_files/track_5/049clark.pdf

Coleman, D., \& Levine, S. (2008). Collaboration 2.0: technology and best practices for successful collaboration in a Web 2.0 world. Cupertino, CA: Happy About.info Publishing Company.

Damianos, E. L., Cuomo, D., Griffith, J., Hirst, D. M., \& Smallwood, J. (2007). Exploring the Adoption, Utility, and Social Influences of Social Bookmarking in a Corporate Environment. In Proceedings of the 40th Hawaii International Conference on System Sciences. IEEE.

Dawson, R. (2009). Implementing Enterprise 2.0: A Practical Guide To Creating Business Value Inside Organizations With Web Technologies. Advanced Human Technologies.

DiMicco, J. M., Geyer, W., Dugan, C., Brownholtz, B., \& Millen, D. R. (2009). People Sensemaking and Relationship Building on an Enterprise Social Networking. In Proceedings of HICSS 2009. IEEE.

Dixon, B. E. (2010). Towards E-Government 2.0: An Assessment of Where E-Government 2.0 is and Where It Is Headed. Public Administration \& Management, 15(2), 418-454.

Doz, Y.L. (1996). The Evolution of Cooperation in Strategic Alliances: Initial Conditions or Learning Processes? Strategic Management Journal, 17, 55-83. doi:10.1002/smj.4250171006
EC. (2002). eEurope 2005: An information society for all. Communication from the Commission $\operatorname{COM}(2002) 263$ final. Retrieved June 22, 2013, from http://eur-lex.europa.eu/LexUriServ/LexUriServ.do?uri=COM:2002:0263:FIN:EN:PDF

EC. (2010). EUROPE 2020 - A strategy for smart, sustainable and inclusive growth. Communication from the Commission - $\operatorname{COM}(2010) 2020$. Retrieved June 22, 2013, from http://ec.europa. eu/eu2020/pdf/COMPLET\%20EN\%20BARROSO $\% 20 \% 20 \% 20007 \% 20-\% 20$ Europe $\% 20$ 2020\%20-\%20EN\%20version.pdf

EC. (2012). Single Market Act II - Together for new growth. Communication from the Commission - COM(2012) 573. Retrieved June 22, 2013, from http://ec.europa.eu/internal_market/smact/ docs/single-market-act2_en.pdf

EC. (2013). Study on Analysis of the Needs for Cross-Border Services and Assessment of the organisational, Legal, Technical and Semantic Barriers. European Commission. Retrieved June 22,2013, from http://ec.europa.eu/digital-agenda/ en/news/final-report-study-analysis-needs-crossborder-services-and-assessment-organisationallegal

Ehrlich, K., \& Shami, N. S. (2010). Microblogging inside and outside the workplace. In Proceedings of 4th International AAAI Conference on Weblogs and Social Media. Washington, DC: AAAI.

EIF. (2010). European Interoperability Framework (EIF) for European public services. Retrieved June, 22, 2013 from http:// eur-lex.europa.eu/LexUriServ/LexUriServ. do?uri=COM:2010:0744:FIN:EN:PDF

EPC. (2010). Digital Single Market Newsletter. Retrieved June 22, 2013, from http://www.epc. eu/dsm/1/Digital_Single_Market.pdf 
Gompert, D. C., \& Nerlich, U. (2002). Shoulder to Shoulder - The Road to U.S. European Military Co-operability: A German American Analysis. RAND Corporation. Retrieved June, 22, 2013, from http://www.rand.org/content/dam/rand/ pubs/monograph_reports/2005/MR1575.pdf

Higuera, R. P., Gluch, D. P., Dorofee, A. J., Murphy, R. L., Walker, J. A., \& Williams, R. C. (1994). AnIntroduction to Team Risk Management. (Version 1.0), Special Report CMU/SEI-94-SR-1, Carnegie Mellon University.

Jackson, A., Yates, J., \& Orlikowski, W. (2007). Corporate Blogging: Building community through persistent digital talk. In Proceedings of the 40th Hawaii International Conference on System Sciences. IEEE.

Johnston, P. (2006). 21st Century Networked Local Government. Cisco Systems. Retrieved June, 22, 2013 from http://www.cisco.com/web/about/ ac79/docs/wp/21st_Century_Networked_Local_Government.pdf

Kaczorowski, W. (Ed.). (2004). Connected Government. London: Premium Publishing.

Kolari, P., Finin, T., Lyons, K., Yesha, Y., Perelgut, S., \& Hawkins, J. (2007). On the structure, properties and utility of internal corporate blogs. In Proceedings of the International Conference on Weblogs and Social Media ICWSM 2007. ICWSM.

Kramer, R. M. (1999). Trust and Distrust in Organizations: Emerging Perspectives, Enduring Questions. Annual Review of Psychology, 50, 569-598. doi:10.1146/annurev.psych.50.1.569 PMID:15012464

McAfee, P. A. (2006). Enterprise 2.0: The Dawn of the Emergent Collaboration. MIT Sloan Management Review, 47(3), 21-28.

McAfee, P. A. (2009). Enterprise 2.0: New Collaborative Toolsfor Your Organization's Toughest Challenges. Cambridge, MA: Harvard Business Publishing.
Mergel, I., Schweik, C., \& Fountain, J. (2009). The Transformational Effect of Web 2.0 Technologies on Government. Retrieved June, 22, 2013 from http://papers.ssrn.com/sol3/papers. cfm?abstract_id=1412796

Meyers, B. C. (2006). Risk Management Considerations for Interoperable Acquisition, TECHNICAL NOTE, CMU/SEI-2006-TN-032. Carnegie Mellon University.

Microsoft. (2011). Connected Government in a Connected World. Microsoft Corp. Retrieved June, 22, 2013 from http://www.microsoft.com/ download/en/details.aspx $? \mathrm{id}=8295$

Misuraca, G., Alfano, G., \& Viscusi, G. (2011). Interoperability Challenges for ICT-enabled Governance: Towards a pan-European Conceptual Framework. Journal of Theoretical and Applied Electronic Commerce Research, 6(1), 95-111. doi:10.4067/S0718-18762011000100007

NUS Institute of Systems Science, National University of Singapore. (2010). Retrieved June 22, 2013, from http://unpan1.un.org/intradoc/groups/ public/documents/unpan/unpan039390.pdf

Ollus, M. (2005). A Holistic Approach towards Collaborative Networked Organizations. In Innovation and the Knowledge Economy: Issues, Applications, Case Studies. IOS Press.

Ollus, M. (2007). Approaches and solutions supporting collaboration in networks. In Proceedings of the International Cluster Conference. Venice, Italy: Academic Press.

Osimo, D. (2008). Web 2.0 in Government: Why and How? JRC Scientific and Technical Reports, European Communities.

Pallab, S. (2010). Understanding the Impact of Enterprise Architecture on Connected Government. Academic Press. 
Parameswaran, M., \& Whinston, A. B. (2007). Social Computing: An Overview. Communications of the Association for Information Systems, 19, 762-780.

Pardo, T. A., Cresswell, M. A., Dawes, S. S., \& Burke, G. B. (2004). Modeling the Social \& Technical Processes of Interorganizational Information Integration. In Proceedings of the 37th Hawaii International Conference on System Sciences. IEEE.

Pardo, T. A., Gil-Garcia, R., \& Burke, G. B. (2006). Building Response Capacity through Cross-boundary Information Sharing: The Critical Role of Trust. In Exploiting the Knowledge Economy: Issues, Applications, Case Studies. Amsterdam: IOS Press.

Pascu, C. (2008). An Empirical Analysis of the Creation, Use and Adoption of Social Computing Applications. JRC Scientific and Technical Reports. European Communities.

Raeth, P., Smolnik, S., Urbach, N., \& Butler, B. (2009). Corporate Adoption of Web 2.0: Challenges, Success, and Impact. In Proceedings of the pre-ICIS 2009 SIM Academic Workshop Enterprise and Industry Applications of Web 2.0. Phoenix, AZ: SIM.

Richter, A., \& Riemer, K. (2009). Corporate Social Networking Sites - Modes of Use and Appropriation through Co-Evolution. In Proceedings of 20 th Australasian Conference on Information Systems Corporate Social Networking Sites. Melbourne, Australia: Academic Press.

Rodriguez, M., Steinbock, D., Watkins, J., Gershenson, C., Bollen, J., Grey, V., \& Degraf, B. (2007). Smartocracy: Social Networks for Collective Decision Making. In Proceeding of the 40th Annual Hawaii International Conference on System Sciences (pp. 90-100). IEEE.
Sari, B., Schaffers, H., Kristensen, K., Loh, H., \& Slagter, R. (2008). Collaborative knowledge workers: Web tools and workplace paradigms enabling enterprise collaboration 2.0. In ECOSPACE IPeProfessional Collaborative Workspace. Dienstag.

Scholl, H. J., \& Klischewski, R. (2007). EGovernment Integration and Interoperability: Framing the Research Agenda. International Journal of Public Administration, 30(8), 889-920. doi:10.1080/01900690701402668

Stewart, K., Clarke, H., Goillau, P., Verrall, N., \& Widdowson, W. (2004). Non-technical Interoperability in Multinational Forces. In Proceedings of 9th International Command and Control Research and Technology Symposium. Copenhagen, Denmark: Academic Press.

Tolk, A. (2003). Beyond Technical Interoperability - Introducing a Reference Model for Measures of Merit for Coalition Interoperability. In Proceedings of the 8th International Command and Control Research and Technology Symposium (ICCRTS). Washington, DC: ICCRTS.

Turban, E., Liang, T. P., \& Wu, S. P. J. (2011). A Framework for Adopting Collaboration 2.0 Tools for Virtual Group Decision Making. Group Decision and Negotiation, 20, 137-154. doi:10.1007/ s10726-010-9215-5

Ubaldi, B. (2011). The impact of the Economic and Financial crisis on e-Government in OECD Member Countries. European Journal of ePractice, 11, 5-18.

UNDESA. (2008). e-Government Survey 2008: From e-Government to Connected Governance. New York: United Nations Department of Economic and Social Affairs.

US-CREST. (2000). Coalition Military Operations - The Way Ahead Through Co-operability. U.S. Center for Research and Education on Strategy and Technology. Retrieved June 22, 2013, from http://www.uscrest.org/CMOfinalReport.pdf 
Wagner, C. (2004). Wiki: A Technology For Conversational Knowledge Management And Group Collaboration. Communications of the Association for Information Systems, 14, 265-289.

Warr, A. W.(2008). Social software: fun and games, or business tools? Journal of Information Science, 34(4), 591-604. doi:10.1177/0165551508092259

Young, O. (2007). Topic Overview: Web 2.0. Forrester Research.

\section{ADDITIONAL READING}

AA.VV. (2004). Current Perspectives on Interoperability. Technical Report, CMU/SEI-2004TR-009 - ESC-TR-2004-009. Carnegie Mellon Software Engineering Institute.

Castelnovo, W. (2008). From Cooperation to Cooperability, Electronic Government, Proceedings of the 7th International Conference(EGOV 2008). Lecture Notes in Computer Science, Vol. 5184, Springer Berlin/Heidelberg. pp. 352-363.

Castelnovo, W. (2011). Risk Management in a Cooperation Context. Proceedings of The 11th European Conference on E-Government, ECEG 2011.

de Kool, D., \& van Wamelen, J. (2008). Web 2.0: A new basis for e-government? Proceedings of the Third International Conference on Information and Communication Technologies: From Theory to Applications. pp. 1-7.

Guijarro, L. (2007). Interoperability frameworks and enterprise architectures in E-Government initiatives in Europe and the United States. Government Information Quarterly, 24, 89-101. doi:10.1016/j.giq.2006.05.003

Husin, M.H., Deegan, G., \& Evans, N. (2012). Social Twins Enterprise 2.0 and Government 2.0. European Journal of ePractice, 17,51-67.
Janssen, M., Charalabidis, J., Kuk, G., \& Cresswell, T. (2011). E-government Interoperability, Infrastructure and Architecture: State of-the-art and Challenges. Journal of Theoretical and Applied Electronic Commerce Research, 6(1), I-VIII. doi:10.4067/S0718-18762011000100001

Luna-Reyes, L., Zhang, J., Gil-Garcia, R. J., \& Cresswell, A. M. (2005). Information Systems Development as Emergent Socio-Technical Change: A Practice Approach. European Journal of Information Systems, 14,93-105. doi:10.1057/ palgrave.ejis.3000524

Mathiassen, L., \& Sørensen, C. (2008). Towards A Theory of Organizational Information Services. Journal of Information Technology, 23(4), 313-329. doi:10.1057/jit.2008.10

Nilsson, A. (2008). Management of Technochange in an Interorganizational e-Government Project. Proceedings of the 41st Hawaii International Conference on System Sciences.

Porta, M., House, B., Buckley, L., \& Blitz, A. (2008). Value 2.0 - Eight new rules for creating and capturing value from innovative technologies. IBM Institute for Business Value.

Punie, Y., Lusoli, W., Centeno, C., Misuraca, G., \& Broster, D. (2009). The Impact of Social Computing on the EU Information Society and Economy. JRC Scientific and Technical Reports, European Communities.

Richter, A., \& Koch, M. (2008). Functions of Social Networking Services. The 8th International Conference on the Design of Cooperative Systems (COOP '08).

Wattiez, A. (2011). An Evaluation of the Critical Success Factors to Implement Enterprise 2.0 Solutions Within Belgian Organizations. Henley - University of Reading. 


\section{KEY TERMS AND DEFINITIONS}

Connected Government: The result of a transformational process that leads Government organizations to achieve a level of integration such that citizens and enterprises can interact with government as with a single entity rather than with a number of different public authorities.

Co-Operability: A form of non-technical interoperability aiming at the successful bridging of differences in doctrine, organization, concepts of operation, and culture so that different organizations can function together essentially as a single organization with no loss in effectiveness.

Cooperation Platform: A set of specific ICT tools and services that supportinter-organizational cooperation.

\section{Cross-Border/Sectorial/Administrative}

Services: Services delivered to citizens and businesses through inter-organizational cooperation and that can be freely accessed irrespective of the agency, department, administration or country that deliver them.
Government 2.0: The use of Web 2.0 services and tools within government organizations as well as their embracing of the collaborative philosophy of Web 2.0.

Interoperability: Ability of disparate and diverse organizations to interact towards mutually beneficial and agreed common goals, involving the sharing of information and knowledge between the organizations, through the business processes they support, by means of the exchange of data between their respective ICT systems.

Social Computing and Cooperation Services and Tools (SC\&CS): ICT applications, based on the Web 2.0 paradigm, that enable people to interact efficiently with other people, as well as to share contents and data through the Web. 